\title{
Complexity problem in immunology
}

\section{Vladimir Zemskov ${ }^{1,2}$, Konstantin Pronko $^{1}$, Andrey Zemskov ${ }^{3}$, and Veronika Zemskova ${ }^{3}$}

1. Department of Research and Development at Facecontrol, Inc., Florida, Miami, USA

2. Clinical Immunology Group, A.V. Vishnevsky National Medical Research Center of Surgery, Moscow,

Russia

3. Department of Microbiology, Burdenko Voronezh State Medical University, Voronezh, Russia

\section{REVIEW}

Please cite this paper as: Zemskov V, Pronko K, Zemskov A, Zemskova V. Complexity problem in immunology. AMJ 2018;11(9):459-464.

https://doi.org/10.21767/AMJ.2018.3490

Corresponding Author:

Vladimir Zemskov

Head of Department of Research and Development at Facecontrol, Inc., Florida, Miami, USA

Email:vzemskov@facecontrol.biz

\section{ABSTRACT}

The article discusses the problem of immune response complexity, found in functional unity of regulatory systems, cooperation of immunocompetent cells, connection and regulation of specific and non-specific defence mechanisms, association of immune, routine laboratory and clinical parameters under normal and pathological conditions. The article reviews the influence of disease combinations, their comprehensive treatment on immunopathology, and the corrector effects. To reproduce natural mechanisms of homeostasis regulation, complex, blocking immunotherapy of diseases is suggested.

\section{Key Words}

Complexity, immunopathology, immunotherapy

\section{What this review adds:}

\section{What is known about this subject?}

The complexity of the immune response with all immune components, laboratory and clinical data, norms and pathologies is discussed for the first time.

\section{What new information is offered in this review?}

For the first time, immune reactions are not considered as autonomous, episodic, simple and linear, but the immune system is not as isolated, but integrated into a complex of other systems - the nervous, endocrine, metabolic system, which was previously a limitation of further progress in immunology.

3. What are the implications for research, policy, or practice?

The implementation of the discussed approaches will contribute to the development of diagnostic and therapeutic technologies in medicine.

\section{Introduction}

Life support of an organism is ensured by functional unity of all its systems, including regulatory ones - nervous, immune, endocrine, etc. ${ }^{1-4}$ The traditional notion that immune responses are autonomous, episodic, unidirectional, simple and linear, the artificial notion of the lymphoid system as something isolated does not correspond to reality and limits the development of diagnostic and treatment technologies. ${ }^{5}$

General evidence of complexity of natural mechanisms of homeostatic regulation in the organism

Functional unity between the immune, nervous and endocrine systems

The first two systems have common functioning principles induction of specific responses, memory, a branched anatomical structure, capacity for modification of other body system functions, presence of common receptors in nerve and lymphoid cells, formation of common biochemical regulators and messengers by these cells. To these should be added the immunotropic activity of sex and other hormones, endocrine-like action of immune mediators, a direct release of peptide hormones by immunocompetent cells, formation of cytokines, and presence of a common biochemical mediator in the functioning of cyclic nucleotides cAMP/cGMP. Any change 
in the cell function of these systems occurs via signals from the external environment, which are realized through molecular receptors for signal molecules of ligands of the same hormones, cytokines, neuromediators, pathogens, etc. ${ }^{6,7}$

Another example of the immune response complexity is the cooperation of immunocompetent cells. ${ }^{8,9}$ A classic example of this process is a trinomial cooperation in the phenomenon of immune response induction. ${ }^{10-12}$

There is also a constant direct or distant interaction between the investing tissue cells and lymphoid cells, the latter and the vessel wall endothelium, T-lymphocytes ( $T$ ) and antigen-recognizing cells, T-cells and B-lymphocytes (B), T-lymphocytes and leukocytes, lymphocytes and leukocytes with intercellular matrix, etc.

Known mechanisms of cell interactions are: (1) Intercellular junctions of membranes - cell adhesion through complementarity of receptors that are long-term (in solid tissues) and short-term (reversible intercellular synapses); (2) Interaction through synthesis and secretion of soluble substances that affect the adhesion in two variants - distant action, for example, through endocrine hormones, and local action - through mediators such as cytokines. Cell adhesion molecules, which bind to the corresponding receptors of target-cells, are selectins, mucin-like vascular addressins, integrins, and immunoglobulin super-family. The result of these interactions is implementation of the core process of immune system functioning - lymphopoiesis.

\section{Complexity of pre-immune and specific defence mechanisms}

It is realized not simultaneously, but stretched in time. ${ }^{13,14}$ In this context, the natural resistance (including species immunity), not part of immune responses, defending the body against chemical, physical, biological pathogenic agents, is a connecting link with specific immune mechanisms, as it prepares antigen for their deployment and its signalling on B-cells. Otherwise, it is difficult to develop active immunity against thymus-dependent antigens.

Non-specific mechanisms develop immediately after penetration of a causative agent and operate constantly throughout the infection process - they are particularly active during the first 4 hours.

They are complex, include generalized responses that are caused by microbicidal digestive enzymes of the intestine, investing tissues, local vascular and temperature responses, cough, nasal catarrh, diarrhoea, perspiration, normal microflora, $\mathrm{pH}$ of skin and mucous membranes, ciliated epithelium, inflammation, etc.

Humoral factors include bactericidal and lytic products of blood serum, tissue fluids, acute phase proteins, complement systems, properdins, lysozyme, $\beta$-lysines, endolysins, plakins, pentraxins, interferons, normal antibodies, pronectins, adhesins, antimicrobial peptides, opsonins, etc.

Cellular responses are caused by a primary pre-immune, food phagocytosis, mast cells, basophils, neutrophils, eosinophils, dendritic cells, monocytes/macrophages, natural killer cells. The second, more powerful stage of antiinfectious protection develops in the period from 4 to 96 hours - an early inducible response, which is caused by the above-mentioned cellular humoral factors, as well as by cytokines that involve new cells into the process, which prepare the development of a specific adaptive immunity (phenomena of recognition, activation, differentiation, proliferation, etc.).

This period is marked by the development of reactions that carry elements of specificity, such as professional phagocytosis, antibody-dependent killing, $\gamma$-interferon. Specific mechanisms begin to develop in the period from 78 days to 2-4 weeks since the appearance of pathogen in the body and realize ITH (immediate-type hypersensitivity), DTH (delayed-type hypersensitivity), immune memory, antibody formation (primary, repeated immune responses), immunodeficiency, phenomena of tolerance, paralysis, deviation, enhancement, formation of sensitized lymphocytes, lymphokines, transplantation immunity, transplant-against-host reaction, immune surveillance. ${ }^{15}$ The notion of complexity also includes the phenomenon of non-specific immune response regulation by thymus and bone-marrow substances (myelopeptides), fragments of immunoglobulins, cytokines, complement system, lipid peroxidation products, carbohydrate and water-salt metabolism, proteins and peptides, enzymes, etc. ${ }^{10,14,16}$

\section{Correlations between immune-and-laboratory and clinical parameters}

Patients with bronchopulmonary diseases demonstrated a definite dependence of clinical and functional characteristics on the type of immunodeficiency. For example in case of IgA deficiency, there was a decrease in TLC (total lung capacity) and VLC (vital lung capacity). The average value of oxygen tension was lower in children with 
hypoxemia than in patients with IgA deficiency. At the same time, clinical manifestations and functional breathing problems in children with chronic bronchopulmonary diseases on the background of isolated Ahypoimmunoglobulinemia unfolded more favourably, and in case of complex immunopathology, they were more severe and extensive. ${ }^{8,10,12}$ Using $\mathrm{Kj}$-coefficient, three leading immune parameters were sampled from patients with secretory otitis media and chronic obstructive bronchitis in the acute period: ${ }^{7,17} \mathrm{~T}$ - and B-lymphocytes, Th (T-helpers) and CTL (cytotoxic T-lymphocytes), IgM, which proved to be correlated with clinical parameters - negative inoculation of microflora, low, 1st-degree conduction of acoustic meatus, myxoedema or fever, coughing, pulmonary rales.

On the clinical model of cortico-dependent bronchial asthma, the key clinical parameters - asthma attacks, cough, shortness of breath, pulmonary rales - were associated with CD3+, CD8+, CD4+, CD19+ lymphocytes. After modulation of patients with sodium nucleinate, the main disease symptoms proved to be dependent on the severity of skin tests for staphylococcal or streptococcal allergens, as well as on the amount of T-cytotoxic lymphocytes.

In patients suffering from urogenital viral infection (UGVI) with chlamydia, ureaplasmosis and trichomoniasis, the significant correlations between lymphocyte phenotype, local and systemic cytokine parameters were determined using the Spearman's coefficient. The combination of UGVI and chlamydia caused 13 associative links of clinical parameters (duration of subjective sensations, period of rash regression, remission, quality of life, clinical index) with a correlation coefficient $(>0.8)$ and with subpopulations of lymphocytes, 14 - with parameters of systemic status and 10 - with local cytokine status, which had a definite pathogenetic and prognostic value. ${ }^{18}$

In children who survived severe asphyxia, ${ }^{19}$ we found a direct correlation between the phagocytic number in the umbilical cord blood and the long rupture-to-delivery interval and the inverse correlation between gestosis and the level of CD95+ lymphocytes, NBTac (active reduction of nitro blue tetrazolium). Positive associative link was observed between gestosis in the maternal organism and CD8+ lymphocytes. Diverse correlations were observed between IgG concentration on the 5th day and breathing disorder, duration of artificial lung ventilation, gestosis, acute renal failure in newborns, and duration of jaundice. We also determined the influence of immune status on the resistance degree in children who survived severe asphyxia. There is a statistically significant negative correlation between the level of $\mathrm{CD} 3+$ lymphocytes and the resistance degree, the index of acute diseases; and the smaller the number of CD4+, CD8+, CD19+ cells, the higher the index of acute diseases. IgA level in the umbilical cord blood correlated with atopic dermatitis and anaemia. The detected correlations between immune parameters and the resistance degree in children under 1 year confirm that the frequency of acute respiratory-viral diseases directly depends on the immunologic responsiveness of children who survived severe asphyxia. As a result of predicting the frequency of acute infectious diseases in the first year of a child's life, a predictive model was constructed, which included 26 immune parameters. The model's predictive power is determined by the determinism coefficient (R2), which describes $77 \%$ of the weight contribution of these parameters to the variability of the acute disease index. ${ }^{19}$

\section{Correlations of immune and laboratory parameters under normal and pathological conditions}

A definite interpretation of existing strong correlations between parameters of laboratory or any other status has not been formulated. It has been suggested that the more correlations between parameters, the worse the functioning of immune system. ${ }^{14,20}$ We hold an opposite point of view, since it was established that the number of correlations of immune and laboratory parameters in clinical remission stage increased after treatment of a wide range of diseases. In principle, this phenomenon is an indirect criterion for evaluation of efficacy of therapeutic interventions. It has been demonstrated that the components of the immune and laboratory status form a certain matrix of integrative connections in healthy individuals - one-time healthy blood donors. Thus, populations and subpopulations of lymphocytes have a direct correlation with the level of total lymphocytes; cells with markers CD3+, CD4+, CD19+ proved to be positively correlated and the phagocytic number negatively correlated with the rod nuclear cells. CD3+, CD4+ lymphocytes were positively dependent on segmented leukocytes.

T-cells were negatively dependent on basophils, CD4+ lymphocytes - on eosinophils, and the phagocytic number was positively dependent on the same cells. ${ }^{15}$ Some correlations between biochemical parameters and parameters of T-component of the immunity system were detected with a predominance of positive correlations over negative ones. And the level of T-lymphocytes had positive correlations with thymol test, hemodiastase, cholesterol, prothrombin, antioxidant activity of blood plasma, activity of superoxide dismutase and negative correlation with ALAT (alanine aminotransferase). T-cytotoxic lymphocytes, 
respectively, - with total and free bilirubin, thymol test, hemodiastase, glucose and also ALAT, T-helpers - with thymol test, prothrombin, antioxidant activity of plasma, and superoxide dismutase. Killer-lymphocytes were dependent on antioxidant activity of plasma and superoxide dismutase. The level of total and conjugated bilirubin, prothrombin, antioxidant activity of plasma and superoxide dismutase had positive correlation with the number of Bcells. Absorbing capacity of leukocytes was under "negative control" from prothrombin, ALAT, thymol test, free and conjugated bilirubin - and under positive control from the cholesterol level. Prothrombin was negatively correlated with the metabolic activity of neutrophils, and total bilirubin, ACAT (aspartate aminotransferase) and total protein - were also correlated, but positively.

Variations of associative processes have a definite expression in diseases. Thus, in children with serous meningitis, T-lymphocytes were positively correlated with the content of leukocytes, segmented cells, monocytes, ALAT; regulatory subpopulations - with T-cells, leukocytes, ALAT; B-cells - with albumin; PI (phagocytic index) with ALAT; PN (phagocytic number) - with $\alpha-1$ and $\beta$-fractions; NBTac with NBTsp (spontaneous reduction of nitro blue tetrazolium). In case of purulent meningitis, the connection between lymphoid cells and monocytes was lost. At the same time, there were positive correlations of immune status components with cholesterol and $\beta$-lipoproteins - in CTL, T-helpers, B-lymphocytes, IgM, NBTsp and NBTac. In principle, integration with protein blood fractions was preserved.

Thus, proceeding from the presented data, the nosological variants of meningitis (serous or purulent) leave their impact on typical changes of the laboratory status components, including integrative processes.

\section{Influence of disease combinations on immunopathology}

The achievement of recent years is the establishment of a wide range of variability of immune reactivity in various diseases, which in turn is the material basis for development of new pathological processes, which requires correction. The situation is regarded as simple when the patient has one disease, but in case of several diseases it becomes controversial, as any particular main diagnosis largely determines the disease treatment. This section presents data on the immunological examination of patients who suffer from a combination of diseases of different and similar genesis, complicated with true and pseudoallergy. ${ }^{9,11,17}$ The subject matters for analysis were the typical formulas of immune system disorders (FISD), including signal laboratory markers, which specify vector and degree of variations from the norm level (Table 1).

The data in Table 1 show that all 13 investigated variants of disease combinations, according to FISD, modify a set of diagnostically significant parameters, which indicate a change in the mechanism of immunopathology. At the same time, in case of combination of diseases of various geneses, we observe mainly the formation of a new-quality response in patients. For example, in case of combination of bronchopulmonary and autoimmune pathologies (idBA+CAIT) into the final formula - $\mathrm{TAT}_{3}^{+} \mathrm{ClC}_{3}^{+} \mathrm{Tx}_{2}^{-}$, idBA "delegated" $\mathrm{CIC}_{+3}$, and CAIT - $\mathrm{TAT}_{+3}$, the same occurs with COPD $+C C\left(\lg _{2}^{-} B_{2}^{-} \operatorname{lgM}{ }_{2}^{+}\right)$- the components of complex pathology $\mathrm{COBB}+\mathrm{CC}$ - only one test hyperimmunoglobulinemia $\mathrm{M}$. In patients with 4 variants of combined pathology of similar genesis, the coincidence of the composition of FISD components was 2 out of 3 parameters, respectively, in case of idBA+CP $-\mathrm{Tx}_{2}^{-} \mathrm{CTL}_{-2} \operatorname{lgG}{ }_{2}^{-}$, idBA - $\mathrm{T}_{2}^{-} \operatorname{lgA} \mathrm{A}_{-2} \mathrm{Tx}_{2}^{-}, \mathrm{CP}-\mathrm{Tx}_{3}^{-} \mathrm{CTL}_{2}^{-} \mathrm{T}_{3}^{-}$. The complication of diseases with true or pseudo-allergy completely changed the composition of FISD benchmarks. The represented data can have fundamental value for clinical practice. So, contrary to expectations, in case of combination of COPD with CLL or with $\mathrm{MM}$, severe lymphoproliferative processes proved to have minimal contribution to the systemic typical immune response of patients.

\section{Influence of disease combinations on the immunocorrection effects}

Combinations and allergisation of diseases turned out to be factors for modification of modulator effects. The drugs of different origin and mechanism of action (synthetic Galavite, native - Sodium nucleinate) were analysed for hematologic, immune, bacteriological, clinical parameters of patients who suffer from mixed-type bronchial asthma (MBA), purulent soft tissue infection (PSTI) in combination with allergic dermatitis (AD), true eczema (TE), COPD, $A D .^{6,7,13,15}$ Signalling targets of the immunocorrection action were similarly determined in patients with mono- and combined pathology in comparative aspect (Table 2).

It was established that the severity of normalization of immune and hematologic tests under the influence of Galavite turned out to be equally significant or moderate in case of PSTI, PSTI+AD, PSTI+TE; the same - bacteriological parameters of moderate severity - in case of two variants of a complicated infection course, the same was observed in patients according to clinical parameters; the same according to clinical parameters of insignificant severity in case of PSTI+AD. Determination of modulator targets 
showed their complete exclusivity, directly correlated with the types of diseases - PSTI - $\mathrm{PN}_{2}^{+} \mathrm{NBTsp}_{2}^{+} \mathrm{ATL}_{2}^{+}$; PSTI+AD $\mathrm{CTL}_{2}^{+} \mathrm{MCM}_{2}^{-} \mathrm{IL} 4_{2}^{+}$; PSTI+TE - NBTac ${ }_{3}^{+} \mathrm{IL}_{4}^{+}{ }_{3} \mathrm{Lph}_{2}^{+}$.

Sodium nucleinate maximally eliminated the presence of hematologic inflammation markers in case of MBA and $M B A+C O P D$, less pronounced - in case of COPD and $M B A+A D$. Correction of immunopathology was insignificant in case of COPD, moderate - in other cases. The clinical effect was equally well present in all cases. The set of key modulator targets turned out to be not so differentiated as in the previous case, but rather individual. In case of MBA, the accumulation of $\mathrm{T}$ - and $\mathrm{B}$-cells of the third degree was predominantly observed, against the background of IgA deficiency - the second degree; in case of COPD - of moderate severity - increased level of T-cytotoxic lymphocytes, IL4 and decrease - MSM. In case of MBA+COPD - leukopenia, T-lymphocytosis, decreased level of proinflammatory Interleukin-6 of 2-3 degrees; in case of $M B A+A D$ - maximum stimulation of anti-inflammatory cytokine concentration, absorbing activity of phagocytes, moderate hypoimmunoglobulinemia $\mathrm{A}$.

The presented data indicate that, on the one hand, there is complete absence of the so-called passport modulator targets, and on the other hand, there is practically the same dependence of these targets on the clinical features of diseases.

\section{Efficacy of combined immunocorrection}

Practice shows that in a number of cases it is necessary to conduct a combined immunotherapy to increase the efficacy of treatment of severe diseases, which, however, re-quires obligatory preliminary approbation of influences. $^{6,9,17,21-26}$ In this case, the selection of drugs for combinations cannot be random, but should be wellfounded. Clinical models of PID (proinflammatory disease) and NILD (non-specific inflammatory lung diseases) of various genesis - deep pyoderma (DP), exacerbation of chronic pyelonephritis (ECPN), exacerbation of chronic salpingooophoritis (ECSO); MBA, MBA+COPD, were used to estimate the clinical and laboratory efficacy of Roncoleukin, Isoprinosine, Licopid, CigaPan, Hypoxen, Superlymph, Derinat, Sodium nucleinate (SN), Thymogen, Gabriglobine, Polyoxidonium, Bronchomunal. After immunotherapy, we conducted an integral evaluation of the changes in hematologic, biochemical, bacteriological, clinical, immune parameters in patients, and using $\mathrm{Kj}^{15}{ }^{15}$ determined the main components of ICTF of conventional disease treatment with mono- and combined therapy.

Integral evaluation showed that in patients with deep pyoderma (PD), traditional therapy (TT) caused significant normalization of hematologic parameters, satisfactory bacteriological, clinical and immune parameters; Roncoleukin - significant normalization of haematological, bacteriological, immune parameters and satisfactory normalization of clinical parameters; Isoprinosine and combination of three modulators - significant normalization of hematologic, bacteriological, clinical parameters and satisfactory - immune; Licopid - significant normalization of hematological, immune parameters, and satisfactory bacteriological and clinical parameters. The patients with ECSO after TT demonstrated significant normalization of biochemical, bacteriological parameters, satisfactory hematologic, immune parameters, unsatisfactory - clinical parameters; after additional prescription of CigaPan or Superlymph - significant - biochemical, bacteriological parameters, satisfactory - haematological, clinical, immune parameters; the same - Derinat or combination of CigaPan with Superlymph and Derinat - significant - haematologic, biochemical, bacteriological, clinical parameters, satisfactory - immune markers of disease. In patients with ECSO, TT provided significant normalization of bacteriological parameters, satisfactory - immune parameters, unsatisfactory - haematological and clinical parameters; Thymogen, Gabriglobine, Thymogen + Gabriglobine + Polyoxidonium - significant - bacteriological and clinical parameters, satisfactory - haematological and immune parameters.

The final rating of decreasing effectiveness of immunotropic treatment in case of DP was as follows: combination of three modulators $\rightarrow$ Licopid $\rightarrow$ further equally - Isoprinosine or Roncoleukin; in case of ECPN - CigaPan + Superlymph + Derinat; Derinat; Superlymph; CigaPan; in case of ECSO Polyoxidonium, Thymogen; Gabriglobine or combination of three correctors. The efficacy of one standard therapeutic method was significantly lower in all cases.

The patients with NILD demonstrated the following results: TT with Hypoxen had moderate effect on immune parameters in case of MBA+COPD; the same with Sodium nucleinate - moderate effect in case of COPD, significant effect - in case of MBA, MBA + COPD; the same with Bronchomunal, moderate effect - in case of MBA, COPD, $\mathrm{MBA}+\mathrm{COPD}$; the same with Bronchomunal + Sodium nucleinate, significant effect - in case of MBA + COPD. Insignificant correction of clinical symptoms of diseases from the level of TT with Hypoxen was registered after the use of Sodium nucleinate, Bronchomunal in case of MBA + COPD; moderate - Bronchomunal in case of COPD, Sodium nucleinate + Bronchomunal in case of MBA + COPD; 
significant - Sodium nucleinate in case of MBA. The established rating of treatment activity showed that in case of MBA, the highest activity was achieved due to the use of $\mathrm{TT}+$ Hypoxen + Bronchomunal $\rightarrow$ further + Hypoxen + Sodium nucleinate $\rightarrow$ further + Hypoxen; in case of COPD - + Hypoxen + Sodium nucleinate + Bronchomunal $\rightarrow+$ Hypoxen; in case of MBA+COPD the maximum efficacy was reached with combination of $\mathrm{TT}+$ Hypoxen + Bronchomunal; further $\rightarrow+$ Hypoxen + Bronchomunal or + Sodium nucleinate. The presented data show the obvious advantage of combined immunotherapy (Table 3 ).

The data in Table 3 indicate that when comparing with regard to TT the ICTF components of 6 variants of combined therapy and 18 variants of monoimmunotherapy of patients suffering from PID and NILD, a certain new quality is formed.

Thus, the complexity of response, regulation, therapeutic correction of immune system function is postulated, which implies cooperation between regulatory systems, immunocompetent and auxiliary cells, systemic and regional immunity, presence of body-wide and specific defence mechanisms, clinical and laboratory parameters; internal and external regulators, active influence on these processes by combination, allergisation of diseases, as well as the distinct advantage of combined immunotherapy of patients.

\section{References}

1. Bernet F. Cellular immunology. Moscow: Mir Publ. 1971;570.

2. Boyd U. Fundamentals of immunology. Moscow: Mir Publ. 1969;469.

3. Kvetnoy IM, Yarilin AA, Polyakova VO. Neuroimmunoendocrinology of the thymus. St. Petersburg: DEAN Publ. 2005;158.

4. Poletayev AB. Immunophysiology and immunopathology. Moscow: Meditsinskoye Informatsionnoye Agenstvo Publ. 2008;207.

5. Zemskov AM, Zemskov VM, Kozlov VA, et al. Nonlymphoid mechanisms of immunopathology. Moscow: Bely bereg Publ. 2007;455.

6. Zemskov AM, Zemskov VM, Karaulov AV, et al. Phenotypic modification of immunological reactivity. Moscow: Pechatnaya zastava Publ. 2010;350.

7. Zemskov AM, Zemskov VM, Chereshnev VA, (ed.) Encyclopedia of immunology, in 5 volumes. Moscow: Triada-X Publ. 2013b;1962.

8. Paul W, (ed.) Immunology in 3 volumes. Moscow: Mir Publ. 1988;1292.

9. Petrov RV. Immunology. Moscow: Meditsina Publ.
1987;414.

10. Galaktionov VG. Immunology. Moscow. 2004;248.

11.Zemskov AM, Zemskov VM, Karaulov AV. Clinical immunology. College textbook. Moscow: GEOTAR-Media Publ. 2008;426.

12. Roit AP, Brostoff J, Male D. Immunology. Moscow. 2000;420.

13. Zemskov AM, Zemskov VM, Karaulov AV. Clinical immunology. Moscow: Meditsinskoye Informatsionnoye Agenstvo Publ. 1999;604.

14.Zemskov AM, Zemskov VM, Zoloedov VI, et al. Unorthodox immunology. Moscow: Triada-X Publ. 2013a;223.

15. Zemskov AM, Zemskov VM, Zemskova VA, et al. Clinical immunologist's handbook. Theoretical, practical and applied aspects of clinical immunology in modern times. Moscow: Triada-X Publ. 2015;704.

16. Prokopenko LG, Brovkina IL. Immunometabolic disorders and their correction. Oxidation, energy and immune homeostasis (disorder and correction). Kursk. 2003;1334.

17. Kalinina NM, Ketlinsky SA, Okovity SV. Immune system diseases. Diagnosis and pharmacotherapy. Moscow: Eksmo Publ. 2008;494.

18. Shabalin AR, Konoplya AI, Gavrilyuk VP. Clinical and immunological aspects of sexually transmitted combined urogenital infection. Belgorod: Izdatelstvo Belgorodskogo gosuniversiteta. 2006;285.

19. Bugrym NV. Features of cellular and humoral immunity in newborns who survived severe asphyxia. Cand. med. sci. Diss., Voronezh. 2011;22.

20. Lebedev KA, Ponyakina ID. Immunodeficiency. Moscow. 2003;390

21.Zemskov AM, Zemskov VM, Chereshnev VA, et al. Clinical immunology guide for practitioners. Moscow: Triada-X Publ. 2011;285.

22. Zemskov AM, Zemskov VM, Karaulov AV, et al. Immunopathology and immunocorrection of nonspecific inflammatory lung diseases. Moscow-Voronezh. 2000;440.

23. Zemskov AM, Zemskov VM, Sergeyev YuV, et al. Thousand formulas of clinical immunology. Moscow: Meditsina dlya vsekh Publ. 2003;332.

24. Novikov DK, Novikov PD. Clinical immunopathology. Moscow: Meditsinskaya literatura Publ. 2009;449.

25. Khaitov RM, Ataullakhanov RI. Immunotherapy. Guidance for doctors. Moscow: GEOTAR-Media Publ. 2012;669.

26. Khaitov RM, Ignatieva GA, Sidorovich IG. Immunology. Norm and pathology. Moscow: Meditsina Publ. 2010;749. 


\section{PEER REVIEW}

Not commissioned. Externally peer reviewed.

\section{CONFLICTS OF INTEREST}

The authors declare that they have no competing interests.

\section{FUNDING}

None 
Table 1: Typical FISD in disease combinations

\begin{tabular}{|c|c|c|c|}
\hline $\begin{array}{l}\text { Diseases of different } \\
\text { genesis }\end{array}$ & FISD & $\begin{array}{l}\text { Diseases of similar } \\
\text { genesis }\end{array}$ & FISD \\
\hline $\mathrm{idBA}+\mathrm{CAIT}$ & $\mathrm{TAT}_{3}^{+} \mathrm{ClC}_{3}^{+} \mathrm{Tx}_{2}^{-}$ & $\mathrm{idBA}+\mathrm{CP}$ & $\mathrm{Tx}_{2}^{-} \mathrm{CTL}_{2}^{-} \lg \mathrm{G}_{2}^{-}$ \\
\hline idBA & $\operatorname{lgG}_{2}^{+} \mathrm{CIC}_{3}^{+} \lg \mathrm{A}_{2}^{-}$ & idBA & $\mathrm{T}_{2}^{-} \lg \mathrm{A}_{2}^{-} \mathrm{Tx}_{2}^{-}$ \\
\hline CAIT & $\mathrm{TAT}_{3}^{+} \operatorname{lgM}_{2}^{-} \mathrm{B}_{3}^{+}$ & $\mathrm{CP}$ & $\mathrm{Tx}_{3}^{-} \mathrm{CTL}_{2}^{-} \mathrm{T}_{3}^{-}$ \\
\hline $\mathrm{COB}+\mathrm{CC}$ & $\lg _{2}^{-} \mathrm{B}_{2}^{-} \lg \mathrm{M}_{2}^{+}$ & $\mathrm{MBA}+\mathrm{COPD}$ & $\mathrm{T}_{2}^{-} \operatorname{lgM}_{2}^{+} \mathrm{L}_{2}^{+}$ \\
\hline $\mathrm{COB}$ & $\mathrm{Tx}_{2}^{-} \mathrm{T}_{2}^{-} \lg \mathrm{M}_{2}^{+}$ & MBA & $\mathrm{L}_{2}^{+} \mathrm{Tx}_{2}^{+} \mathrm{T}_{2}^{-}$ \\
\hline $\mathrm{CC}$ & $\operatorname{lgA}_{2}^{+} \operatorname{lgG}{ }_{2}^{-} \operatorname{IgM}_{3}^{+}$ & COPD & $\mathrm{T}_{2}^{-} \mathrm{MWM}_{3}^{+} \mathrm{CTL}_{2}^{+}$ \\
\hline $\mathrm{COB}+\mathrm{CLL}$ & $\mathrm{Lph}_{3}^{+} \operatorname{lgM}_{3}^{+} \operatorname{lgG}_{3}^{-}$ & $\mathrm{GU}+\mathrm{DU}$ & $\operatorname{lgG}_{2}^{+} T_{2}^{-} \lg A_{2}^{-}$ \\
\hline $\mathrm{COB}+\mathrm{MM}$ & $\mathrm{T}_{2}^{+} \mathrm{CTL}_{3}^{+} \lg \mathrm{A}_{3}^{+}$ & DU & $\mathrm{T}_{2}^{-} \lg \mathrm{G}_{2}^{+} \lg \mathrm{A}_{2}^{-}$ \\
\hline CLL & $\mathrm{T}_{3}^{+} \mathrm{Lph}_{3}^{+} \mathrm{CTL}_{3}^{+}$ & $\mathrm{GU}$ & $\mathrm{T}_{2}^{-} \lg \mathrm{A}_{2}^{-} \mathrm{Lph}_{2}^{+}$ \\
\hline FIC & $\operatorname{lgA}_{2}^{-} \operatorname{lgM_{2}^{-}} \operatorname{lgG_{2}^{+}}$ & FIC & $\lg A_{2}^{-} \lg M_{2}^{-} \lg G_{2}^{-}$ \\
\hline FIC + obesity & $\mathrm{T}_{2} \lg \mathrm{G}_{2} \lg \mathrm{A}_{2}^{-}$ & FIC + ENT & $\mathrm{CTL}_{2}^{+} \lg \mathrm{M}_{2}^{-} \lg \mathrm{A}_{2}^{-}$ \\
\hline $\begin{array}{l}\text { Diseases + } \\
\text { true allergy }\end{array}$ & FISD & $\begin{array}{l}\text { Diseases }+ \\
\text { pseudo-allergy }\end{array}$ & FISD \\
\hline$M B A+A D$ & $\mathrm{IL} 4_{3}^{+} \mathrm{PN}_{3}^{+} \lg \mathrm{A}_{2}^{-}$ & $\mathrm{COB}+\mathrm{PA}$ & $\mathrm{Pl}_{2}^{-} \mathrm{Lph}_{2}^{-} \mathrm{B}_{2}^{-}$ \\
\hline MBA & $\mathrm{L}_{2}^{+} \mathrm{Tx}_{2}^{+} \mathrm{T}_{2}^{-}$ & $\mathrm{COB}$ & $\mathrm{Tx}_{2}^{-} \mathrm{T}_{2}^{-} \lg \mathrm{M}_{2}^{-}$ \\
\hline
\end{tabular}

Conventional signs: idBA - infectious-dependent bronchial asthma, CAIT - chronic autoimmune thyroiditis, COB - chronic obstructive bronchitis, CC - chronic cholecystitis, CLL -chronic lymphocytic leukemia, MM - multiple myeloma, CP - chronic pneumonia, MBA -mixed-type bronchial asthma, COPD - chronic obstructive pulmonary disease, GU - gastric ulcer. DU duodenal ulcer, AD - allergic dermatitis, PA - pseudo-allergy, FIC - frequently ill children, FIC + ENT - the same + diseases of Ear, Nose, and Throat. At the top of formulas: + (increase), - (decrease), at the bottom of formulas - degree of variation (1 insignificant, 2 - significant and 3 - very significant); TAT- thyroglobulin autoantibodies, CIC - circulating immune complexes, L - leukocytes, MWM - medium-weight molecules, Lph - Lymphocytes

Table 2: Clinical and laboratory effect of modulators in case of PID (proinflammatory disease) in ranks

\begin{tabular}{|c|c|c|c|c|c|c|}
\hline \multirow{3}{*}{$\begin{array}{l}\text { Nosological } \\
\text { forms }\end{array}$} & \multicolumn{4}{|c|}{ Parameters } & \multirow{3}{*}{$\begin{array}{c}\text { Sum of ranks/ level of } \\
\text { efficacy ** }\end{array}$} & \multirow{3}{*}{ ICTFs } \\
\hline & Hematologic & Immune & Bacteriological & Clinical & & \\
\hline & \multicolumn{4}{|c|}{ Ranks* } & & \\
\hline \multicolumn{7}{|c|}{ Galavite (Gal) } \\
\hline PSTI & 2 & 3 & 1 & 1 & $7 / 1$ & $\mathrm{PN}_{2}^{+} \mathrm{NBTsp}_{2}^{+} \mathrm{ATL}_{2}^{+}$ \\
\hline PSTI + AD & 2 & 3 & 2 & 3 & $10 / I I I$ & $\mathrm{CTL}_{2}^{+} \mathrm{MCM}_{2}^{-} \mathrm{IL}_{2}^{+}$ \\
\hline PSTI + TE & 2 & 3 & 2 & 2 & $9 / 11$ & $\mathrm{NBTac}_{3}^{+} \mathrm{IL}_{3}^{+}{ }_{3} \mathrm{Lph}_{2}^{+}$ \\
\hline \multicolumn{7}{|c|}{ Sodium nucleinate (SN) } \\
\hline MBA & 1 & 2 & - & 1 & $4 / 1$ & $\mathrm{CD}^{+}{ }_{3} \mathrm{CD}_{19}{ }_{3}^{+} \lg \mathrm{A}_{2}^{-}$ \\
\hline COPD & 2 & 3 & - & 1 & $6 / I I I$ & $\operatorname{lgA}_{3}^{-} \mathrm{CD}_{19^{+}} \mathrm{CD}_{3}^{+}{ }_{3}$ \\
\hline $\mathrm{MBA}+\mathrm{COPD}$ & 1 & 2 & - & 1 & $4 / 1$ & $\mathrm{~L}_{3}^{-} \mathrm{CD}_{3}^{+}{ }_{3} \mathrm{IL6}_{2}^{-}$ \\
\hline$M B A+A D$ & 2 & 2 & - & 1 & $5 / 11$ & $\mathrm{IL}^{+}{ }_{3} \mathrm{PN}_{3}^{+} \lg \mathrm{A}_{2}^{-}$ \\
\hline
\end{tabular}

Conventional signs: * rank1 - significant change (stimulation or suppression) $>66 \%$ of the parameters; rank 2 - >33-66\% of the parameters; rank 3 -<33\% of the parameters; ** level of efficacy: I - insignificant, II - moderate, III - significant. ICTFs "self" immune correction targets formula, independent of the basic treatment of diseases. The lower the sum of ranks, the higher the effectiveness of treatment; IL - interleukins, Lph - Lymphocytes with expression of LFA-1 integrin receptors 
Table 3: ICTF of differentiated therapy of PID and NILD

\begin{tabular}{|c|c|c|c|c|c|}
\hline Diseases & Modulators & ICTF & Diseases & Modulators & ICTF \\
\hline \multirow{4}{*}{ DP } & Roncoleukin & $\mathrm{ATL}_{3}^{+}{ }_{3} \mathrm{gGG}_{3}^{-} \mathrm{T}_{3}^{+}$ & \multirow{4}{*}{ MBA } & Hypoxen & $\mathrm{Lph}_{2}^{+} \operatorname{lgM}_{2}^{+} \mathrm{Tx}_{2}^{+}$ \\
\hline & Isoprinosine & $\mathrm{NKt}_{3}^{+} \mathrm{NKr}_{3}^{+}{ }_{3} \mathrm{IL}^{+}{ }_{3}$ & & Bronchomunal & $\mathrm{Tx}_{3}^{+} \mathrm{T}_{2}^{+} \mathrm{B}_{2}^{+}$ \\
\hline & Licopid & $\mathrm{PI}_{3}^{+} \mathrm{NBTac}_{3}^{+} \mathrm{IL6}_{3}^{-}$ & & Sodium nucleinate & $\mathrm{T}_{3}^{+} \mathrm{CTL}_{3}^{+} \mathrm{EO}_{2}^{-}$ \\
\hline & Combination & NBTsp ${ }_{3}{ }^{-} \mathrm{CTL}_{3}^{+} \mathrm{Tx}_{3}^{+}$ & & Combination & $\mathrm{PN}_{3}^{+} \mathrm{IL}_{4}^{+}{ }_{3} \mathrm{Eo}_{3}^{-}$ \\
\hline \multirow{4}{*}{ ECPN } & CigaPan & $\mathrm{NBTsp}_{3}^{+} \mathrm{PN}_{3}^{+} \mathrm{NKr}_{3}^{+}$ & \multirow{4}{*}{ COPD } & Hypoxen & $\operatorname{lgG}_{3}^{-} \lg \mathrm{A}_{3}^{-} \mid \mathrm{L4}_{2}^{+}$ \\
\hline & Superlymph & $\mathrm{NKr}_{3}^{+} \mathrm{NKt}_{3}^{+} \mathrm{IL}_{4}^{+}{ }_{3}$ & & Bronchomunal & $\mathrm{RTL}_{2}^{+} \operatorname{lgM}_{2}^{+} \mathrm{CTL}_{2}^{+}$ \\
\hline & Derinat & $\mathrm{RTL}_{3}^{+} \mathrm{B}_{3}^{+} \mathrm{CTL}_{3}^{+}$ & & Sodium nucleinate & $\mathrm{L}_{3}^{-} \mathrm{PN}_{2}^{-} \mathrm{IL}_{2}^{-}$ \\
\hline & Combination & $\mathrm{Tx}_{3}^{+} \mathrm{RTL}_{3}^{+} \mathrm{ClC}_{3}^{-}$ & & Combination & $\mathrm{MCM}_{3}^{-} \mathrm{ClC}_{3}^{-} \mathrm{T}_{3}^{+}$ \\
\hline \multirow{4}{*}{ ECSO } & Thymogen & $\mathrm{Tx}_{3}^{+} \mathrm{CTL}_{3}^{+} \mathrm{NKr}_{3}^{+}$ & \multirow{4}{*}{$\mathrm{MBA}+\mathrm{COPD}$} & Hypoxen & $\operatorname{lgG}_{3}^{+} \mathrm{T}_{3}^{-} \mathrm{L}_{3}^{-}$ \\
\hline & Gabriglobine & $\operatorname{lgA}_{3}^{+} \mathrm{PI}_{3}^{+} \mathrm{B}_{2}^{+}$ & & Bronchomunal & $\mathrm{NK}_{2}^{+} \operatorname{lgG}{ }_{2}^{+} \mathrm{RTL}_{2}^{+}$ \\
\hline & Polyoxidonium & $\mathrm{RTL}_{3}^{+} \mathrm{NBTsp}_{3}^{+} \mathrm{PN}_{3}^{+}$ & & Sodium nucleinate & $\mathrm{PN}_{3}^{+} \mathrm{NBTsp}_{2}^{-} \mathrm{IL8}_{2}^{-}$ \\
\hline & Combination & $\mathrm{Tx}_{3}^{+} \mathrm{ATL}_{3}^{+} \mathrm{MCM}_{3}^{+}$ & & Combination & $\mathrm{Lph}_{3}^{+} \mathrm{T}_{2}^{+} \mathrm{NBTac}_{3}^{+}$ \\
\hline
\end{tabular}

Conventional signs: see above, inter alia: ATL - activated T-lymphocytes, NKT - natural killers thymus-dependent, NKr natural killer regulators, RTL - regulatory T-lymphocytes 